S.M. Yasir Arafat ${ }^{*}$, Sujita Kumar Kar², Vikas Menon³, Marthoenis Marthoenis ${ }^{4}$, Pawan Sharma $^{5}$, Angi Alradie-Mohamed ${ }^{6}$, Srijeeta Mukherjee ${ }^{7}$, Charanya Kaliamoorthy $^{3}$, Russell Kabir ${ }^{6}$

\title{
Media portrayal of panic buying: A content analysis of online news portals
}

\author{
'Department of Psychiatry, Enam Medical College and Hospital, Dhaka-1340, Bangladesh \\ 2Department of Psychiatry, King George's Medical University, Lucknow-226003, U.P., India \\ ${ }^{3}$ Department of Psychiatry, Jawaharlal Institute of Postgraduate Medical Education and Research (JIPMER), Puducherry-605006, India. \\ 4Department of Psychiatry and Mental Health Nursing, Universitas Syiah Kuala, Banda Aceh 23111, Indonesia \\ ${ }^{5}$ Department of Psychiatry, School of Medicine, Patan Academy of Health Sciences, Lalitpur, Nepal \\ ${ }^{6}$ School of Allied Health, Faculty of Health, Education, Medicine, and Social Care, Anglia Ruskin University, Chelmsford, United Kingdom \\ ${ }^{7}$ Department of Psychiatry, MKCG Medical College, Brahmapur, Odisha-760004, India. \\ *email: arafatdmc62dagmail.com
}

DOI: $10.2478 / g p-2020-0022$

Received: 29 July 2020; Accepted: 15 August 2020

\begin{abstract}
Objectives: Media reporting has an influential role in panic buying $(P B)$. We aimed to evaluate the media portrayal of PB during this COVID-19 pandemic.

Methods: We searched, collected, and analysed the news reports from the English media discussing the PB events. The search was done between 23 and 30 May 2020.

Results: A total of 525 news reports were analysed. Approximately half (49.3\%) discussed the government action to handle the situation, 36.4\% discussed the expert opinion regarding $P B, 20.6 \%$ discussed the psychology of PB, 21.5\% discussed the rumours, and $18.5 \%$ suggested remedial measures. Concerning the negative aspects, 96.6\% of the titles mentioned panic buying, $75.4 \%$ mentioned the cause, and 62.3\% mentioned the photos of empty shelves. The media in low-middle-income countries are 1.5 times more likely to include expert opinion ( $p=0.03)$, 2.1 times more likely to discuss rumours regarding $P B(p=0.001)$, almost thrice more likely to report the cause of $P B(p=0.001)$, and thrice more likely to mention its impact $(p=0.001)$.

Conclusion: Media has been portraying more negative aspects of $P B$. Further, there are variations in reporting patterns between highincome and low-middle-income countries.
\end{abstract}

\section{Keywords}

Panic buying, media report, content analysis

\section{INTRODUCTION}

Panic buying $(\mathrm{PB})$ is an interdisciplinary phenomenon that has been observed episodically during several public health emergencies and disasters (Arafat et al., 2020a; Jennings et al., 2008; Bonneux and Van Damme, 2006). Although this phenomenon overlaps among multiple disciplines such as behavioural science, marketing, supply chain management, economics, sociology, public health, political administration, disaster, and emergency management, there is a dearth of empirical studies explaining it (Arafat et al., 2020b). During the COVID-19 pandemic, it has been observed across the continents irrespective of the income category of countries (Arafat et al., 2020a; Sim et al., 2020). Speculatively, this widespread phenomenon has been explained on the basis of a sense of perceived scarcity, a way of gaining control over the uncertainties, social learning, and also by lack of confidence in the authorities during the PB episodes (Arafat et al., 2020c; Yuen et al., 2020).

The media has an important role in spreading as well as controlling PB (Arafat et al., 2020b). Media can spread news as well as rumours. They can display the photos of empty shelves indicating the scarcity of goods, specify the goods and increase tension, anxiety, and fear among the general population, resulting in a further increase in PB (Arafat et al., 2020b). Conversely, media can also distribute healthy messages to reduce fear, to modify the social cognition in a positive direction, nullify the rumours, and increase the confidence of general people towards the local and national authorities (Arafat 
et al., 2020b). In the situation of PB, the decisions of purchasing by consumers are influenced by peer choices. Hence social learning has an important role in consumers' PB decisions and media can shape and decide this learning by its widespread reach (Zheng et al., 2020). One previous study revealed that $46 \%$ of the media reports mentioned the item related to $\mathrm{PB}$, $82 \%$ mentioned the causes, $67.3 \%$ showed the images of empty shelves, and about $10 \%$ blamed the government (Arafat et al., 2020a). On the other hand, $27.1 \%$ of the reports discussed the remedial measures of $\mathrm{PB}$ and $30.8 \%$ of reports discussed the underlying psychology (Arafat et al., 2020a).

$\mathrm{PB}$ is a newsworthy issue, and media portrayal should be sensible. Positive reporting on $\mathrm{PB}$ discussing the authority (government) action, expert opinion, underlying psychology, nullifying the rumours, suggesting remedial measures, and mentioning the impact of $\mathrm{PB}$ could change the behaviour in a positive direction. Negative presentation of reports on $\mathrm{PB}$ mentioning the term "panic buying", showing the photos of empty shelves indicating the shortage, referring to previous events, blaming the public and/or business persons and government, and dramatizing could potentially increase the behaviour. A study in China reported that spreading rumours created negative emotions, which in turn stimulated people to indulge in PB (Hou et al., 2020). Another study conducted in Iraq also reported that social media posts increased anxiety and PB (Ahmad \& Murad, 2020). In India, goods were sold in black markets in response to PB (Singh \& Rakshit, 2020). In lowand middle-income countries (LMICs), people usually have mistrust of the public representatives and government, which increases during emergency situations as a result of small pieces of rumour (Hossain et al., 2020). Therefore, a cautious approach is warranted when reporting the news on $\mathrm{PB}$ especially during the pandemic. There is a dearth of literature on how media portrays $\mathrm{PB}$ throughout the world. Hence, we aimed to evaluate the media portrayal of $\mathrm{PB}$ during this COVID-19 pandemic. We divided the positive and negative aspects of reporting and also aimed to see any variation in reporting on the basis of the income category of the country.

\section{METHODS}

We conducted the study in two phases. In the initial phase, we assessed the nature, extent, and impact of $\mathrm{PB}$ as reported in the media. We also did the feasibility study as to whether it is possible to get contextual information from media reports of PB during phase I. Subsequently, we tried to identify reporting characteristics of $\mathrm{PB}$ along with the country-wise variations of reporting on $\mathrm{PB}$.

\section{Data collection}

All the search engines have been identified by the investigators. Three independent investigators searched the allotted search engines using the "panic buying" keyword. We searched, collected, and analysed the news reports published in English discussing the PB. The search was done between 23 and 30 May 2020. All online news articles, channel interviews, news forums, personal views, and panel discussions (online published nonvideo reports) were included. Journal articles, journal posts, and social media posts were excluded. After the data collection was completed, two independent researchers carried out crosschecks of the data and data cleaning. Duplications were checked and removed by tracing the date of publication and title of the reports. Also, we removed the responses that were analysed in the initial phase study (Arafat et al., 2020a).

\section{The instrument}

We used the same instrument that was developed during our previous study (Arafat et al., 2020a). The instrument included country of publication of the report, country to which the news report relates, type of newspaper, newspaper name, area (city) of publication, dates of publication, the scarce object for panic purchase, media report material, and relation to similar events of panic purchase in the past. The news that reported no specific countries, multiple countries, or a mix between developing and developed countries was excluded from the analysis. We evaluated the positive and negative aspects of media reporting based on the contents available in the reports. The list of positive and negative aspects was finalized prior to the beginning of data analysis by the process of consensus building between the authors (qualified psychiatrists/public health experts with clinical and research experience of working with $\mathrm{PB}$ ) based on the face validity of selected queries.

\section{Data analysis}

We compared the reporting patterns in the countries divided on the basis of the Human Development Index report by the UNDP. In terms of percentages and proportions, the data collected were presented. A chi-square test was used to make distinctions between the LMICs and high-income countries (HICs). The p-value of $<0.05$ was found important in this analysis. 


\section{RESULTS}

\section{Distribution of the reports}

From 23 May until 30 May 2020, a total of 525 news reports regarding PB were analysed. The vast majority of the news came from the US (22.1\%), followed by the UK (18.5\%), India (15\%), and Australia (5.5\%). Each of the other countries has in total less than 10 reports. Approximately half of the news (48\%) specified the scarce object in the report. The scarce objects include essential medicines, masks, hand sanitizers, gloves, toilet paper, groceries, fuels, food grains, and even firearms and ammunition. Concerning the context of $\mathrm{PB}$ news, the vast majority were related to the recent COVID-19 pandemic (95\%) and the remaining include disasters and economic events (1\%) and other events such as festivals, fuel price hike, and even war $(<1 \%)$.

\section{Positive characteristics of the reports}

Concerning the positive aspects of news content posts related to $\mathrm{PB}$, approximately three-fourth of the news mention the impact of the PB (71\%) and approximately half (49.3\%) discuss the government action to handle the PB issues. Furthermore, around one-third (36.4\%) discuss the expert opinion regarding $\mathrm{PB}$ and approximately one-fifth discuss the psychology of PB (20.6\%), the rumour about PB (21.5\%), and suggest the remedial measures (18.5\%).

\section{Negative characteristics of the reports}

Concerning the negative aspects of the news content, the vast majority of post titles refer to $\mathrm{PB}(96.6 \%)$ and approximately three-fourth of the news mention the cause (75.4\%). Pictures or images of people in line for purchasing stuff or empty groceries were also common (62.3\%). The public's PB behaviour was blamed by around a quarter of the news posts (26.3\%). People involved in business also became the object of blame by some media (9.3\%). Meanwhile, a few media blamed the government for the $\mathrm{PB}$ action (8\%). The details of the content analysis are summarized in Table 1.

\section{Country-wise variations}

Media in LMICs were 1.5 times more likely to include expert opinion with regard to ongoing $\mathrm{PB}(\mathrm{x} 2=4.7, \mathrm{p}=0.03)$ and 2.1 times more likely to discuss the rumour regarding $\mathrm{PB}(\mathrm{x} 2=$ $11.4, \mathrm{p}=0.001)$ as compared to HICs. However, the media in LMICs were almost thrice more likely to report the cause of $\mathrm{PB}(\mathrm{x} 2=14.3, \mathrm{p}=0.001)$ and also thrice more likely to mention
Table 1. Distribution of news reports ( $n=525)$.

\begin{tabular}{|c|c|c|c|}
\hline No. & Variable & $\mathbf{N}$ & $\%$ \\
\hline \multirow[t]{3}{*}{1} & Country of report & & \\
\hline & High and very high income countries & 131 & 25 \\
\hline & Low-middle-income countries & 394 & 75 \\
\hline \multirow[t]{17}{*}{2} & Content of report & & \\
\hline & Positive & & \\
\hline & Discuss the government action & 259 & 49.3 \\
\hline & Discuss the expert opinion & 191 & 36.4 \\
\hline & Discuss the psychology of PB & 108 & 20.6 \\
\hline & Discuss about the rumour* & 113 & 21.5 \\
\hline & Suggest remedial measures & 97 & 18.5 \\
\hline & Mention the impact of PB & 373 & 71 \\
\hline & Negative & & \\
\hline & Title of news post refers to PB & 525 & 96.6 \\
\hline & Mention the cause of PB & 396 & 75.4 \\
\hline & Show the picture or image of PB & 327 & 62.3 \\
\hline & $\begin{array}{c}\text { Refer to similar incident elsewhere or in } \\
\text { the past }\end{array}$ & 163 & 31 \\
\hline & Media blame the public & 138 & 26.3 \\
\hline & Media blame people involved in business & 49 & 9.3 \\
\hline & Media dramatize PB & 46 & 8.7 \\
\hline & Media blame the government & 42 & 8 \\
\hline \multirow[t]{6}{*}{3} & Search engine & & \\
\hline & Bing & 168 & 32 \\
\hline & Yahoo & 110 & 20.9 \\
\hline & Google & 101 & 19.3 \\
\hline & Others & 146 & 27.7 \\
\hline & Total & 525 & 100 \\
\hline
\end{tabular}

the impact of $\mathrm{PB}(\mathrm{x} 2=19.6, \mathrm{p}=0.001)$ as compared to HICs. Meanwhile, the media in HICs and very HICs were almost twice more likely to report similar incidents in the past or elsewhere $(\mathrm{x} 2=7.63, \mathrm{p}=0.005)$. The details of the crude odds ratio of each content of news reports and their association are presented in Table 2.

\section{DISCUSSION}

Panic buying is an emerging entity with a dearth of empirical studies exploring its various aspects. The current study aimed at analysing the media reports of PB under different heads like positive and negative along with country wise (high-income vs. low-income countries) media reporting. The current study revealed that events of $\mathrm{PB}$ were mostly related to the recent COVID-19 pandemic (95\%); however, they were also related to disasters (1\%), festivals, fuel price hike, and even war $(<1 \%)$. The scarce objects include essential medicines, masks, hand sanitizers, gloves, toilet paper, groceries, fuels, food grains, and 
Table 2. The association between content of reported news on PB and the Human Development Index of countries.

\begin{tabular}{|c|c|c|c|c|c|}
\hline \multicolumn{6}{|c|}{ Country Human Development Index } \\
\hline & $\begin{array}{l}\text { Low-Middle } \\
\text { Income (n, } \\
\% \text { ) }\end{array}$ & $\begin{array}{l}\text { High Income } \\
\text { (n, \%) }\end{array}$ & OR $(95 \% \mathrm{CI})$ & $\mathrm{x} 2$ & p-value \\
\hline \multicolumn{6}{|l|}{ Content of report } \\
\hline \multicolumn{6}{|l|}{ Positive } \\
\hline Discuss the government action & $71(54.2)$ & $188(47.7)$ & $1.2(0.8-1.9)$ & 1.65 & 0.19 \\
\hline Discuss the expert opinion & $58(44.3)$ & $133(33.8)$ & $1.55(1.01-2.37)$ & 4.7 & $0.03^{*}$ \\
\hline Discuss the psychology of PB & 19 (14.5) & $89(22.6)$ & $0.5(0.3-1.01)$ & 3.93 & 0.047 \\
\hline Discuss about the rumour* & $42(32.1)$ & $71(18)$ & $2.14(1.33-3.43)$ & 11.4 & $0.0001^{*}$ \\
\hline Suggest remedial measures & $34(26)$ & 64 (16.2) & $1.80(1.08-2.96)$ & 6.11 & 0.013 \\
\hline Mention the impact of PB & $113(86.3)$ & $260(66)$ & $3.23(1.85-5.89)$ & 19.64 & $0.0001 *$ \\
\hline \multicolumn{6}{|l|}{ Negative } \\
\hline Title of news post refers to PB & 130 (99.2) & 377 (95.7) & $5.86(0.89-246.7)$ & 3.74 & 0.053 \\
\hline Mention the cause of PB & $115(87.8)$ & $281(71.3)$ & $2.89(1.61-5.45)$ & 14.3 & $0.0001 *$ \\
\hline Show the photo of PB & $73(55.7)$ & $254(64.5)$ & $0.69(0.45-1.05)$ & 3.2 & 0.07 \\
\hline Refers to similar incident elsewhere or in the past & $28(21.37)$ & 135 (34.3) & $1.91(1.18-3.17$ & 7.63 & $0.005^{*}$ \\
\hline Media blame the public & $42(32.1)$ & $96(24.4)$ & $1.46(0.92-2.30)$ & 3 & 0.083 \\
\hline Media blame people involved in business & $18(13.7)$ & $31(7.9)$ & $1.8(0.94-3.58)$ & 4.01 & 0.045 \\
\hline Media dramatize PB & $8(6.1)$ & $38(9.6)$ & $0.60(0.23-1.37)$ & 1.54 & 0.21 \\
\hline Media blame the government & 15 (11.5) & $27(6.8)$ & $1.75(0.8-3.55)$ & 2.82 & 0.09 \\
\hline
\end{tabular}

even firearms and ammunition. Although there is a dearth of studies on PB, a nearly similar pattern was found in a previous study in respect of the distribution of reports and proportions of positive and negative characteristics of media reporting (Arafat et al., 2020a).

The current study revealed differences in reporting patterns when compared between the countries on the basis of income. The media in LMICs were 1.5 times more likely to include expert opinion with regard to ongoing $\mathrm{PB}(\mathrm{p}=0.03)$ and 2.1 times more likely to discuss the rumour regarding $\mathrm{PB}(\mathrm{p}=$ 0.001) as compared to HICs. However, the media in LMICs were almost thrice more likely to report the cause of $\mathrm{PB}$ ( $\mathrm{p}=$ 0.001 ) and also thrice more likely to mention the impact of $\mathrm{PB}(\mathrm{p}=0.001)$ as compared to HICs. Meanwhile, the media in HICs and very HICs were almost twice more likely to report similar incidents in the past or elsewhere $(\mathrm{x} 2=7.63, \mathrm{p}=0.005)$ when compared to the LMICs (Table 2).

The major findings of the study were that media reporting of $\mathrm{PB}$ was imbalanced and the tone and tenor of the reports were mostly negative. Highlighting panic buying in the title, mentioning the cause of $\mathrm{PB}$, and illustrating the report with photographs of people involved in $\mathrm{PB}$ were some of the commonly observed negative and undesirable reporting characteristics. In contrast, positive aspects of reporting such as mentioning the impact of $\mathrm{PB}$, discussing corrective governmental steps, and educative aspects such as expert opinions and explaining the psychology behind $\mathrm{PB}$ were less frequently observed. Overall, the phenomenon of $\mathrm{PB}$ was more commonly reported from high-income nations as opposed to LMICs. A systematic review on PB suggests that $\mathrm{PB}$ is influenced by a perceived threat, scarcity of products, fear of the unknown, and social and psychological factors of individuals' social networks (Yuen et al., 2020). All these factors are in turn influenced by media. Hence, it is imperative to understand the positive and negative reporting practices.

The above results suggest that media may be unwittingly contributing to the phenomenon of $\mathrm{PB}$ by virtue of their imbalanced reporting focus. Although there are no comparable reports analysing media coverage of $\mathrm{PB}$, some parallels can be drawn with extant literature on media reporting of suicides, which is another phenomenon of immense public health relevance. Repeated studies revealed that media reports have been playing an influential role in the events involving general people such as suicide contagion and mass psychogenic illness. There might be a similar role of media in PB. However, further studies are needed to explain the degree and direction of influence.

\section{What is already known}

Media reporting has an influential role in PB from spreading the behaviour to controlling it (Arafat et al., 2020b). There are no comparable reports analysing media coverage, and there is also a scarcity of evidence exploring the media portrayal of PB. 


\section{What this study adds}

To the authors' best knowledge, this is the first study to report the media portrayal of $\mathrm{PB}$. The paper also assessed the variations of media reporting on the basis of income of countries. Although a large number of expert opinions and media reports have been published as non-scientific literature, this study is among the handful of scientific studies that have looked into an important area of media reporting of $\mathrm{PB}$.

\section{Study limitations}

The current study has several limitations. First, we only included the reports published in English. The reports in non-English languages have been completely excluded, which represent a significant chunk of media reports. Second, there might be biases regarding the country reporting the $\mathrm{PB}$ as the search engines tend to pick up the news that is read widely. The PB present in small countries with limited Internet access and less powerful websites might have been missed in this study. The search for reports is based on the search engine; the more popular the website for reporting, the more the chance to be picked up. Third, the psychometric property of the instrument was not tested.

\section{Recommendations}

Certainly, empirical studies exploring its several aspects are warranted to understand the phenomenon as well as to consider its negative effects. Also, further studies in this area from the consumer perspective are needed as well (Habel et al., 2020). There is a need for reporting guidelines for the $\mathrm{PB}$ as it is a mass behaviour and occurs mostly at the time of public health or other emergencies. As there is no guideline that addresses the media reporting on $\mathrm{PB}$, we may suggest several recommendations such as that media should not sensationalize the mass panic behaviours like $\mathrm{PB}$, catastrophize, and post the photos and videos of scarce objects and empty shelves. Side by side, media should avoid blaming, address the worries, anger, and frustration of mass people, avoid mentioning the public reaction in news reports, and avoid interrogating people on sensitive matters related to $\mathrm{PB}$.

\section{Challenges}

Certain aspects of PB may be the potential source of challenges such as that the behaviour is usually sudden, happens during emergency events, the items could vary, the behaviour could be rational, and the problem is under-researched (Arafat et al., 2020d; Tsao et al., 2019; Kulemeka, 2010). Moreover, it is fundamentally difficult to predict the event (Arafat et al., 2020d; Tsao et al.,
2019; Kulemeka, 2010). However, mentioning the negative characteristics in the reports would increase fear and insecurity, which in turn increases $\mathrm{PB}$ and destroys the equilibrium. At the same time, reporting the helpful characteristics could reduce fear and insecurity even though there is a shortage. For example, if the media mentions that the government is trying to maintain the supply, then fear may be reduced.

\section{Future directions}

Panic buying is a dynamic phenomenon. As the COVID-19 pandemic progresses, the needs of people change and disaster preparedness also changes. The media also lose interest in $\mathrm{PB}$, and the focus moves to other important things as the pandemic progresses. There is a need for the sequential evaluation of media reports on PB to gain better insight into this topic.

\section{CONCLUSION}

The finding suggests that the media have been portraying more negative aspects of $\mathrm{PB}$ and there are variations in reporting when compared between HICs and LMICs. Speculatively, we suggest the formulation and implementation of media guidelines, which could be beneficial in controlling episodes of $\mathrm{PB}$ in the population.

\section{ACKNOWLEDGEMENTS}

None

\section{AUTHORS' CONTRIBUTION}

Conception \& design: SMY Arafat, SK Kar, V Menon

Acquisition of data: C Kaliamoorthy, S Mukherjee, A AlradieMohamed

Data analysis: M Marthoenis

Drafting of the manuscript: SMY Arafat, SK Kar, V Menon, P Sharma, M Marthoenis, R Kabir

Critical revision of the manuscript: All authors

Final approval of the manuscript: All authors

\section{CONFLICT OF INTEREST}

None. Although SMY Arafat is an editorial board member he had no influence on peer review and acceptance. 


\section{DECLARATION OF ETHICS}

The study was conducted complying with the declaration of Helsinki (1964). As already published papers have been reviewed, no formal ethical approval was obtained.

\section{DECLARATION OF INFORMED CONSENT}

Not applicable

\section{FUNDING}

None

\section{REFERENCES}

Ahmad, A.R., Murad, H. R. (2020). The Impact of Social Media on Panic during the COVID-19 Pandemic in Iraqi Kurdistan: Online Questionnaire Study. Journal of Medical Internet Research, 22(5), 19556.

Arafat, S.Y., Kar, S.K., Menon, V., Kaliamoorthy, C., Mukherjee, S., Alradie-Mohamed, A., Sharma, P., Marthoenis, M., Kabir, R. (2020a). Panic buying: An insight from the content analysis of media reports during COVID-19 pandemic. Neurology, Psychiatry and Brain Research, 37, 100-103.

Arafat, S.M.Y., Kar, S.K., Kabir, R. (2020b).Possible Controlling Measures of Panic Buying During COVID-19. International Journal of Mental Health and Addiction. https://doi.org/10.1007/s11469020-00320-1

Arafat, S. M. Y., Kar, S. K., Marthoenis, M., Sharma, P., HoqueApu, E., Kabir, R. (2020c). Psychological underpinning of panic buying during pandemic (COVID-19). Psychiatry Research, 289, 103061.

Arafat, S.Y., Kar, S.K., Menon, V., Sharma, P., Marthoenis, M., Kabir, R. (2020d). Panic buying during COVID-19 pandemic: A letter to the editor. Annals of Indian Psychiatry. https://doi.org/10.4103/aip.aip_48_20.

Bonneux, L., Van Damme, W. (2006). An iatrogenic pandemic of panic. BMJ, 332 (7544), 786-788.

Habel, J., Jarotschkin, V., Schmitz, B., Eggert, A., Plötner, O. (2020). Industrial buying during the coronavirus pandemic: A crosscultural study. Industrial Marketing Management, 88, 195-205.

Hossain, M. S., Ferdous, S., Siddiqee, M. H. (2020). Mass panic during Covid-19 outbreak- A perspective from Bangladesh as a high-risk country. Journal of Biomedical Analytics, 3(2), 1-3.

Hou, Z., Du, F., Jiang, H., Zhou, X., Lin, L. (2020). Assessment of public attention, risk perception, emotional and behavioural responses to the COVID-19 outbreak: social media surveillance in China. Risk Perception, Emotional and Behavioural Responses to the COVID-19 Outbreak: Social Media Surveillance in China (3/6/2020)

Jennings, L. C., Monto, A. S., Chan, P. K., Szucs, T. D., Nicholson, K. G. (2008). Stockpiling prepandemic influenza vaccines: a new cornerstone of pandemic preparedness plans. The Lancet Infectious diseases, 8(10), 650-658.

Kulemeka, W. (2010). US Consumers and Disaster: Observing "Panic Buying" During the Winter Storm and Hurricane Seasons. Advances in Consumer Research, 37, eds. Margaret C. Campbell, Jeff Inman, and Rik Pieters, Duluth, MN : Association for Consumer Research, 837-838.

Sim, K., Chua, H. C., Vieta, E., Fernandez, G. (2020). The anatomy of panic buying related to the current COVID-19 pandemic. Psychiatry Research, 288, 113015

Singh, C.K., Rakshit, P. (2020). A Critical Analysis to comprehend Panic buying behaviour of Mumbaikar's in COVID-19 era. Studies in Indian Place Names, 40(69), 44-51.

Tsao, Y. C., Raj, P. V. R. P., \& Yu, V. (2019).Product substitution in different weights and brands considering customer segmentation and panic buying behavior. Industrial Marketing Management, 77 209-220

Zheng, R., Shou, B., Yang, J. (2020). Supply disruption management under consumer panic buying and social learning effects. Omega, 102238.

Yuen, K. F., Wang, X., Ma, F., \& Li, K. X. (2020). The Psychological Causes of Panic Buying Following a Health Crisis. International Journal of Environmental Research and Public Health, 17(10), 3513. 